\title{
Domestic Wastewater and the Sodium Factor
}

\author{
by Robert A. Patterson $\mathrm{PhD}$ \\ Lanfax Laboratories \\ Armidale. NSW. Australia
}
This paper was presented by Dr Patterson to the
American Society for Testing and Materials,
New Orleans, La. U.S.A.
16th January, 1997.

\begin{abstract}
Copyright of this paper is held by ASTM and was published in a Special Technical Publication 1324, May 1997.
\end{abstract}

REFERENCE: Patterson, R.A. 1997 "Domestic Wastewater and the Sodium Factor", Site Characterization and Design of On-Site Septic Systems, ASTM STP 1324, M.S. Bedinger, A.I. Johnson, and J.S. Fleming, Eds., American Society for Testing and Materials, 1997 pp 23 - 35.

(C) Lanfax Laboratories. Armidale NSW Australia

Phone 61267751157 Web site www.lanfaxlabs.com.au 


\title{
DOMESTIC WASTEWATER AND THE SODIUM FACTOR
}

REFERENCE: Patterson, R.A. "Domestic Wastewater and the Sodium Factor", $\underline{\text { Site }}$ Characterization and Design of On-Site Septic Systems, ASTM STP 1324, M.S. Bedinger, A.I. Johnson, and J.S. Fleming, Eds., American Society for Testing and Materials, 1997 pp $23-35$.

\begin{abstract}
Alternative wastewater treatment systems combat many on-site disposal problems, but no incentives are given to householders to improve the domestic wastewater quality before treatment or disposal. While governments address phosphorus reduction programs, the effect of sodium in wastewater is ignored. Many laundry detergents use sodium salts as fillers, adding significant sodium to the wastewater. This paper addresses the sources of sodium in household products and examines the impact of sodium rich wastewater on various soil profiles. A loss of soil hydraulic conductivity results from the use of sodic wastewater in disposal fields. Simply by changing laundry products, a reduction of up to $38 \%$ of the current sodium concentrations in domestic wastewater can be achieved at no cost to the consumer with no negative impact on household operations. Many environmental benefits accrue, including increased efficiency of on-site disposal.
\end{abstract}

KEYWORDS: domestic wastewater, drain fields, laundry products, on-site systems, sodic wastewater, sodium, soil hydraulic conductivity.

\section{INTRODUCTION}

The individual household of the 1990's is totally reliant upon water for not only personal hygiene but also for the transportation of household wastes to distant treatment systems. Personal hygiene includes disposal of faecal materials and urine, ablutions and clothes washing while general household water use includes washing floors, cleaning and preparing food, washing cooking utensils and flushing unwanted materials away in the wastewater stream. An essential element of domestic water use is the consumption of 
chemicals to assist the washing action of clean water (abrasives, laundry detergents and soaps), bleaches and bactericides as well as the disposal of other chemicals used on the body (powders, make-up, deodorisers, toothpaste) and in the kitchen (detergents, oils and greases, tea leaves). The chemicals which are part of the food chain partly decompose in the wastewater treatment system to release nitrates, phosphates and a complex array of other chemicals, alter the $\mathrm{pH}$ of the wastewater stream and increase the 5-day biochemical oxygen demand $\left(\mathrm{BOD}_{5}\right)$ during aerobic degradation and finally impinge upon the effectiveness of secondary treatment of the effluent in the soil.

In areas beyond the economic reach of reticulated systems, on-site disposal allows householders the convenience of improved sanitation facilities. The options for those households can be met by:

(a) the separation of grey and black water; the grey water to be disposed of with minimal treatment and the black water offered basic treatment before disposal to the soil mantle;

(b) the use of composting toilets in place of total wastewater collection and the minimal treatment of grey water before disposal to the soil mantle;

(c) the use of a conventional septic tank offering primary treatment to all wastewater and disposal of the effluent to subsoil disposal; or

(d) the use of an aerated wastewater treatment system (AWTS) followed by surface disposal of a pre-chlorinated effluent.

The terms wastewater and effluent are not synonymous. Wastewater refers to the untreated composite of water and wastes (solids and liquids) collected within the house-hold and moved in the wastewater stream to a treatment plant. Effluent is liquid emanating from a treatment system after primary or higher treatment which is available for further treatment or disposal. For septic tank systems, the chemical properties of the wastewater will impart a similar chemistry to the effluent as the tank provides primary treatment only.

This paper addresses the implication of wastewater chemistry from individual households utilising all-waste septic tanks and sub-soil disposal system. The problems of ultimate disposal to the soil mantle for options (c) and (d) are examined in relation to the increased sodium concentration, a quality imparted through the use of sodium-rich chemicals in the house. Quantitative data on current wastewater practices will be used to indicate the sources of increases in sodium and the effect upon sodium adsorption ratios (SAR) and their implications upon soil hydraulic conductivity.

Measures to reduce the sodium concentration in domestic wastewater will be discussed in relation to the most easily reduced sources of sodium within the household.

Domestic Wastewater and the Sodium Factor - R.A. Patterson (1997) 


\section{Environmental Impact of Sodium}

Sodium is an essential biological chemical which takes part in processes maintaining osmotic pressure in living cells, plant and animal. An excess of sodium disturbs the critical balance and in humans excess salt (sodium chloride) intake has been linked to heart disease and high blood pressure. In plants, excess sodium leads to a perceived drought effect and plants will show "burnt edge" effects and eventually die. Salt tolerance is a characteristic of many plants but for agronomic purposes, including landscaping and wastewater reuse options, significant losses in plant quality and production arise from increased sodium in the plants' environment.

Animals are tolerant to larger concentrations of sodium. It is common for sheep and cattle to eat soil, scraping the hard soil with their teeth, where salt extrusions occur along gully lines. Many animals also prefer salty ground water to clean rainwater.

For soil disposal of effluent, sodium has been widely reported as reducing the saturated hydraulic conductivity (Ksat) by dispersing the soil clay minerals (Quirk and Schofield, 1955), reducing porosity and increasing the risk of poor movement of water through the soil. Although the hydraulic capacity of the soil is considered important is dealing with on-site effluent disposal, the resultant failure of the soil system during continued loading leads to chemicals in the effluent reaching the broader environment. The chemicals which can escape include nitrogen, phosphorus and sodium salts. Bacterial contamination of the surrounding environment is also a consequence of the hydraulic failure and is often reported in runoff below heavily populated septic tank drain fields (Woodward, 1987).

Sodium in many Australian soils is inherently high, Exchangeable Sodium Percentage (ESP) values above 5 are considered sodic and more likely to disperse than soils below that value (McIntyre, 1979). The use of ESP>15 as a measure of sodicity as adopted from USA is not appropriate to Australian soils. There is, however, a complication caused by the impact of electrical conductivity (EC) on the dispersion factor. Jayawardane (1979) cited a number of studies showing that a reduction of EC or an increase in SAR of the percolating solution resulted in an increase in clay swelling, a change in pore size distribution (Jayawardane and Beattie, 1979) and a decrease in Ksat (Quirk and Schofield, 1955).

\section{Wastewater Quality}

An indicator of effluent quality for disposal to soil is the sodium adsorption ratio of the infiltrating water and the exchangeable sodium percentage (ESP) of the soil to which the effluent is applied. The SAR is a comparison of the concentration of sodium salts that affect dispersion to a combination of the calcium and magnesium salts, the latter ameliorate dispersion (causes flocculation), although high concentrations of magnesium may also cause dispersion with some clays. The ESP is the relative proportion of sodium ions on the exchange sites on the colloidal materials (clays and organic material).

Domestic Wastewater and the Sodium Factor - R.A. Patterson (1997) 


\section{Clean water affects on sodium budget}

Treated water from town water supplies, rainwater and groundwater are often neglected in the mass balance of the chemical loading for domestic water. Town water is available to a large proportion of the population of New South Wales (NSW) and is the primary supply of water to the wastewater stream. While guidelines for drinking water quality are currently in use in Australia (NHMRC, 1994), there is considerable variation across northern New South Wales indicating the varying levels of water quality from "clean water" sources.

Sodium salts are used in water treatment systems to improve $\mathrm{pH}$ (sodium hydroxide), coagulate calcium and magnesium to reduce hardness (sodium carbonate) for the addition of fluoride (sodium fluorosilicate) and the ion exchange removal of heavy metals (sodium aluminosilicate or zeolite). Sodium (sodium chloride) is used to reverse flush ionic exchange units during recharge. Because most sodium salts are soluble in cold water, sodium is an ideal carrier of anions for precipitation of nuisance colloids.

\section{$\underline{\text { Household sodium budget }}$}

Sodium in the household is derived from foodstuffs, cooking additions and numerous chemicals which utilise the high solubility of sodium salts. The amounts of common salt used in the human diet are but small contributors to the overall sodium budget and it is doubtful that large reductions in common salt use within the home will lead to significant changes to sodium in wastewater discharges.

A significant source of sodium is from the laundry detergents, particularly the standard, nonconcentrated powders which use various sodium salts as active ingredients and as fillers. The fillers provide no worthwhile contribution to the wash but may provide up to $40 \%$ of the sodium salts in the wastewater.

\section{$\underline{\text { Soil hydraulic conductivity }}$}

Several methods are employed for measuring the hydraulic conductivity (Ksat) of a soil horizon. The percolation test as designed by Ryon in USA has been used in Australian up until recent times even though its use was widely discontinued in USA more than 20 years ago. It was seen as an easily replicated test with simple conversions to long term acceptance rates (LTAR). The percolation test should not be used for septic tank disposal field design.

A disc permeameter as designed by CSIRO is a useful tool for short term investigative research into the behaviour of Ksat of soils. When using the device, it is difficult to limit the movement of water to a vertical profile and care must be given to site selection, setup and a limitation place upon the duration of tests. Unfortunately subsurface discontinuities may render many of the results worthless. The results outlined here were determined using the disc permeameter on in-situ soils.

Domestic Wastewater and the Sodium Factor - R.A. Patterson (1997) 


\section{RESEARCH METHOD}

\section{Clean Water Inputs}

A survey of 62 town water supplies was undertaken throughout northern and coastal New South Wales (approx. Lat. $30^{\circ} \mathrm{S}$ ) as a one-time sample of water with respect to sodium. Rain water was monitored from several rainwater tanks in the Armidale area. Ground water records from Lanfax Laboratories were used to reveal a trend of water quality that was correlated to aquifer geology.

\section{$\underline{\text { Septic Tank Effluent }}$}

Effluent samples were taken from 50 septic tanks in a rural residential area around Armidale. Together with other parameters measured during sampling (crust depth, sludge depth, persons using facility, period since last pump-out) the study was used to derive a typical septic tank effluent for a rainwater supplied household. A questionnaire survey of 140 households was also undertaken to determine typical management and loading of the wastewater systems, particularly the use of washing machines and laundry detergents.

\section{$\underline{\text { Sewage Treatment Works Effluent }}$}

Effluent samples were taken from 14 sewage treatment works (STW) and compared with the clean water input to those systems. The differences in concentrations were used to derive a likely increase in sodium from domestic use of water.

\section{Laundry Detergents}

A range of powder and liquid laundry detergents was selected from supermarkets in Armidale. The 43 brands, representing the products of 15 manufacturers, consisted of 20 powders, one additive, six concentrates, four soaps and 12 liquids. The products were mixed in water in a ratio comparable to that of a single full load in a top loading automatic washing machine as recommended by the product manufacturer. The samples were analysed for a range of chemical properties ( $\mathrm{pH}, \mathrm{EC}$ and cations).

\section{$\underline{\text { Ksat Determinations }}$}

Simulated effluents made to replicate SAR 1, 3, 8 and 15 conditions and of low EC similar to septic tank effluent were used to infiltrate through soils. Various tests included - standard percolation test, disc permeameter on in-situ soils and a laboratory method developed for treating undisturbed cores.

While many of the soil tests are unreliable, it was necessary to show how the impact of sodic wastewater distorted the percolation rates obtained using clean water as suggested by the current Australian standard.

Domestic Wastewater and the Sodium Factor - R.A. Patterson (1997) 


\section{RESULTS AND DISCUSSION}

\section{Clean Water Inputs}

Reticulated water--That clean water is of a consistent quality for the purposes of estimating impact of water on the soil is not supported by data presented in Figure 1.There was a significant difference in water quality from coastal to inland river systems, additional salts in inland systems reflecting the lower rainfall and higher levels of geological salts

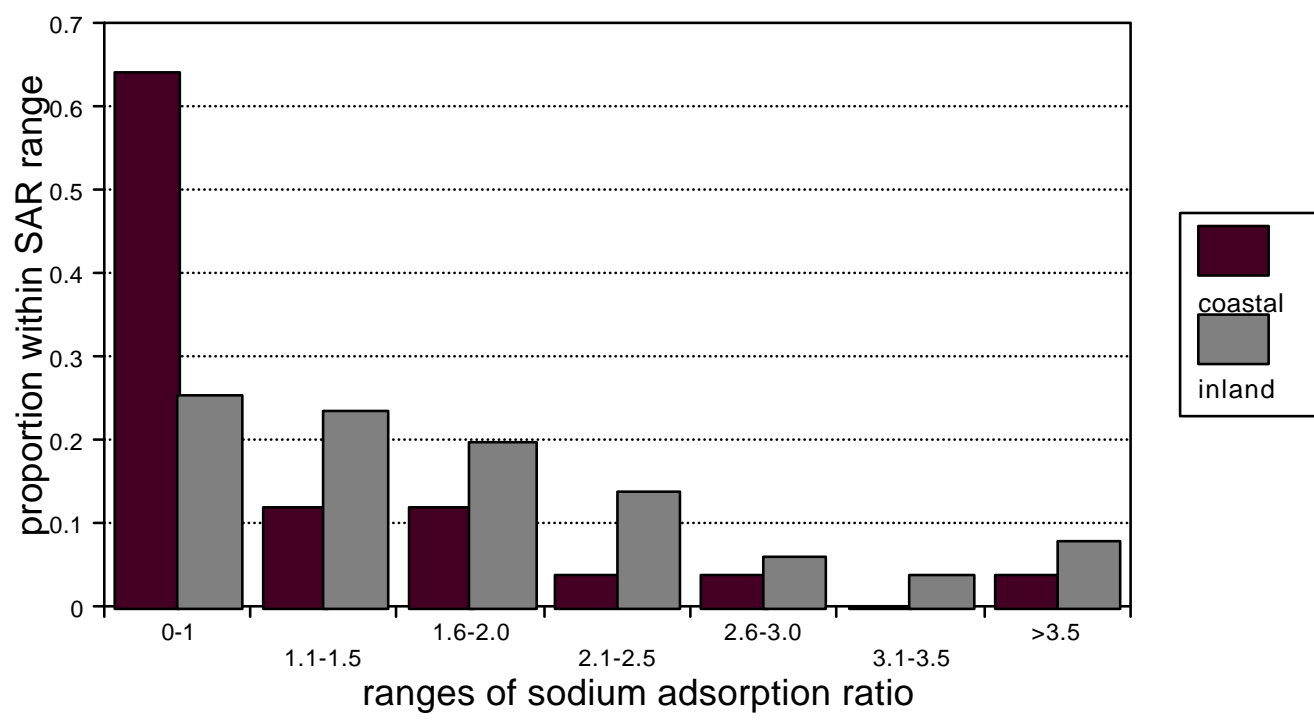

FIG. 1-Variation in sodium adsorption ratios in town water across New South Wales as at July 1991 (62 town supplies).

The SAR values averaged $1.1 \pm 0.2(\mathrm{CV} \mathrm{85 \% )}$ and $2.2 \pm 0.5(\mathrm{CV} 177 \%)$ for the coastal and inland supplies, respectively. Seven inland samples exceeded SAR 3 at which soil Ksat problems are likely to arise. It has been shown from discussions between the author and participants at Wastewater Disposal Training Courses, that few Councils have any records of the SAR of the town water supply or the impact of treatment on the raw water supply with respect to sodium additions. Thus, this important contribution of sodium into the environment through the wastewater disposal is poorly appreciated.

Rainwater--Variations in rainwater quality are not significant, the greatest variation being for salt inputs along the seaboard and from additional calcium salts leaching from new concrete water storage tanks. In the majority of tank water samples analysed, rain water EC varied by less than $0.05 \mathrm{dS} \mathrm{m}^{-1}$ with an average total dissolved salt (TDS) content of less than $10 \mathrm{mg} \mathrm{L}^{-1}$. The sodium input from rainwater is minimal.

Domestic Wastewater and the Sodium Factor - R.A. Patterson (1997) 
Groundwater--Groundwater quality in the New England Tablelands varies significantly in chemistry depending upon the geology of the aquifers (Table 1). The use of groundwater for domestic purposes is more pronounced during extended dry periods when it is used to supplement scarce rainwater reserves. During periods when sufficient rainwater is available for normal domestic purposes, groundwater is used for gardening, toilets and outside purposes. Where the clean water input to the household above is from a resource other than rainwater, the cumulative effects of all input water must be tallied.

TABLE 1--Water quality from aquifers in sediments, granites and basalts in New England

\begin{tabular}{lcccc}
\hline Parameter & $\begin{array}{c}\text { Sodium } \\
\mathrm{mg} \mathrm{L}^{-1}\end{array}$ & SAR & $\begin{array}{c}\text { TDS } \\
\mathrm{mg} \mathrm{L}^{-1}\end{array}$ & $\begin{array}{c}\text { Hardness } \\
\mathrm{mg} \mathrm{L}^{-1}\end{array}$ \\
\hline median & 26 & SEDIMENTS & & \\
\hline range & 2 to 203 & 0.1 to 5.2 & 34 to 2418 & 6 to 518 \\
\hline \multicolumn{5}{c}{ GRANITES } \\
\hline median & 67 & 1.6 & 861 & 358 \\
\hline range & 9 to 143 & 0.5 to 3.2 & 135 to 1870 & 31 to 535 \\
\hline & & BASALTS & & \\
\hline median & 49 & 0.8 & 982 & 454 \\
\hline range & 9 to 181 & 0.7 to 2.7 & 220 to 2650 & 80 to 1403 \\
\hline
\end{tabular}

Septic Tank Effluent Quality

The variations in chemical composition of the septic tank effluent (STE) are due to use of different chemicals within the home and the different dilution factors as determined by the quantity of water consumed per day. Typical STE quality from houses supplied by rainwater inputs are shown in Table 2.

\section{Typical Increase in Sodium From Domestic Use}

The treatment of wastewater from large scale residential developments results in STW effluent either being released back into the river system or available for irrigation on land. The results of the survey (Fig. 2) indicate the relative increase in sodium, the change from the shorter bar to the longer bar with respect to each STW is the impact of the additions and removals of sodium, calcium and magnesium. Increases in sodium ranged from low increases of $40 \mathrm{mg} \mathrm{L}^{-1}$ in inland supplies to high increases of $80-90 \mathrm{mg} \mathrm{L}^{-1}$ in coastal supplies. An average increase in sodium concentration as a result of domestic use of water was $63 \pm 3 \mathrm{mg} \mathrm{L}^{-1}$, taking the average sodium for STW effluent to $96.3 \pm 6 \mathrm{mg} \mathrm{L}^{-1}$.

The environmental effects of the sodium in the STW effluent will lead to an increase in 
sodicity in the river system or impinge upon the physical and biological properties of the soil to which it is disposed. It is shown later that where an effluent having an SAR 3 is disposed to soil, a reduction in Ksat is likely to occur. The scale of sodium additions indicates the sodium loads in tonnes per day from each $5 \mathrm{ML}$ effluent per day for the selected works (Table 3). The total contribution from each town must be equated with the actual volume of discharge. Armidale, a city of 23000 persons is currently (Spring, 1996) discharging about 9 ML per day.

TABLE 2--Chemistry of domestic septic tank effluent

\begin{tabular}{lccc}
\hline Variables & Mean \pm SE & Range & Coeff. Var. (\%) \\
\hline Calcium & $33 \pm 37$ & $7-166$ & 79 \\
\hline Chloride & $182 \pm 16$ & $48-506$ & 61 \\
\hline $\mathrm{EC}\left(\mathrm{dS} \mathrm{m}^{-1}\right)$ & $1.4 \pm 0.1$ & $0.5-5.0$ & 55 \\
\hline Hardness & $131 \pm 17$ & $29-217$ & 90 \\
\hline Magnesium & $12 \pm 2$ & $2-1.9$ & 143 \\
\hline pH & $7.1 \pm 0.1$ & $6.4-8.7$ & 5.1 \\
\hline Phosphorus & $14.4 \pm 0.8$ & $3.7-30$ & 38.6 \\
\hline Potassium & $35 \pm 4$ & $14-180$ & 78.2 \\
\hline SAR & $3.6 \pm 0.3$ & $0.7-9.6$ & 48.9 \\
\hline Sodium & $84 \pm 6$ & $26-318$ & 53.4 \\
\hline
\end{tabular}

$\mathrm{SE}=$ Standard error, upper and lower ranges equivalent to $95 \%$ confidence interval All values are in milligrams per litre unless otherwise shown

TABLE 3--Contribution to sodium budget from domestic sources (tonnes $\mathrm{NaCl}$ equivalent per year for $5 \mathrm{ML}$ discharge per day)

\begin{tabular}{|l|c|c|c|}
\hline Location & Town water & STW effluent & Domestic Input \\
\hline Coffs Harbour (coastal) & 32 & 338 & 306 \\
\hline Armidale (Tablelands) & 127 & 330 & 203 \\
\hline Moree (inland) & 148 & 394 & 246 \\
\hline Dubbo (inland) & 283 & 589 & 306 \\
\hline
\end{tabular}




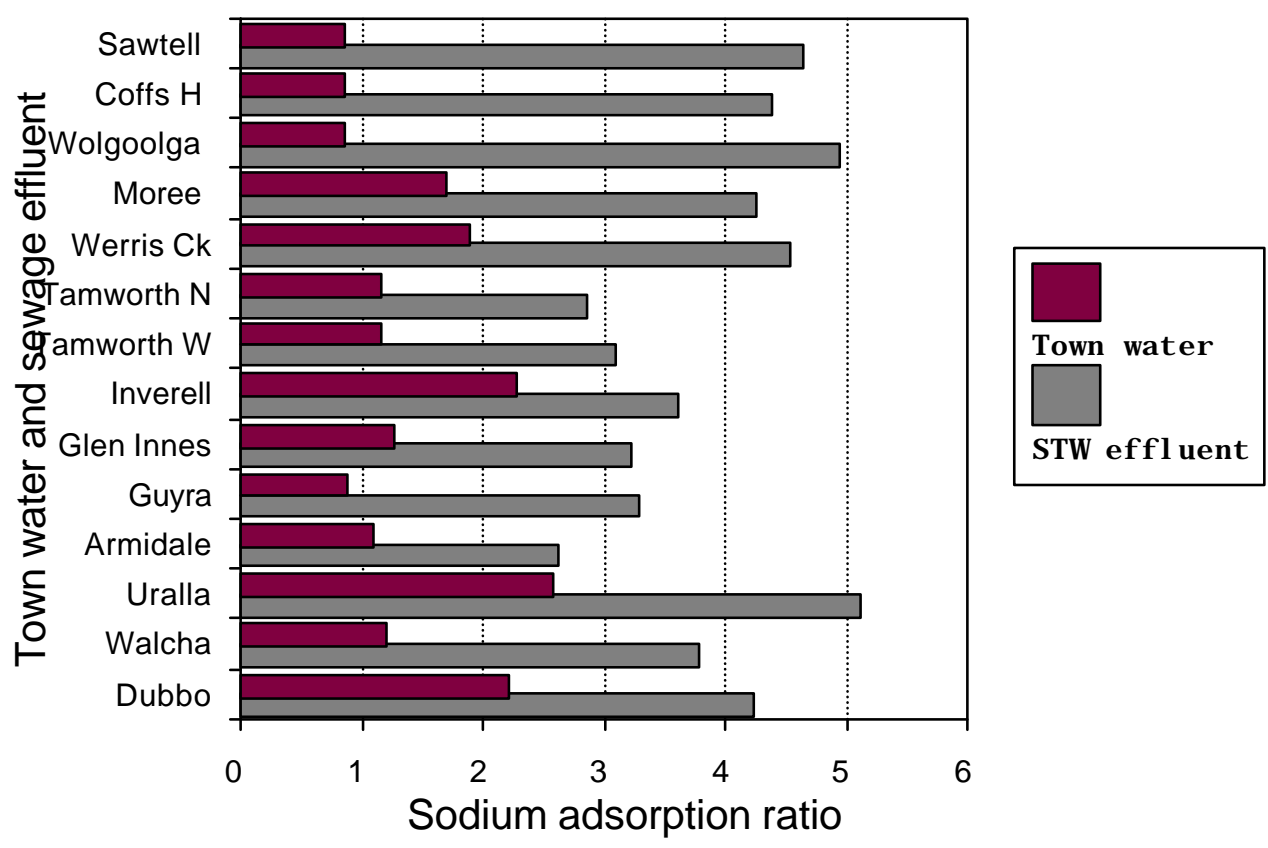

FIG. 2. --Comparison of SAR for selected STW effluents

\section{Laundry Products}

The quantity of powder or liquid recommended for a single wash varied significantly with product. Powders ranged from 48 to $360 \mathrm{~mL}$ for a normal wash and liquids ranged from 85 to $250 \mathrm{~mL}$. From the household survey, $80 \%$ of houses used top loading automatic washing machines for an average of 7.3 full wash loads per week. The detergent brands in order of preference were Omo (15), Amway (12) Cold Power and Surf (7), Radiant, Drive and Fab (6) and other brands were chosen by fewer households.

The contribution of sodium from the laundry products (Fig. 4) indicates the wide range of SAR levels per wash depending upon the product used. It is desirable that the choices of laundry products for septic tanks are taken from the lower range products, particularly when the clean water input also has a large sodium load.

In terms of sodium per wash, $67 \%$ of detergents produced more than $35 \mathrm{~g}$ of sodium per wash, equivalent to $89 \mathrm{~g}$ of common salt (sodium chloride). Only nine samples produced less than $10 \mathrm{~g}$ of sodium per wash, of which seven were liquid detergents. For a household washing seven full loads of washing per week and an average laundry detergent, a typical drainfield would accept about $30 \mathrm{~kg}$ equivalent sodium chloride per year, based on the sodium increase in the STE of $84 \mathrm{mg} \mathrm{L}^{-1}$, of which up to $28 \mathrm{~kg}$ could be from laundry products. By choosing a product from the lower range of sodium detergents, this salt load could be reduced by up to $62 \%$. A reduction in the total household sodium load of $38 \%$ is easily achievable through a choice of a low sodium detergent even where the household is only currently using an average sodium detergent. 


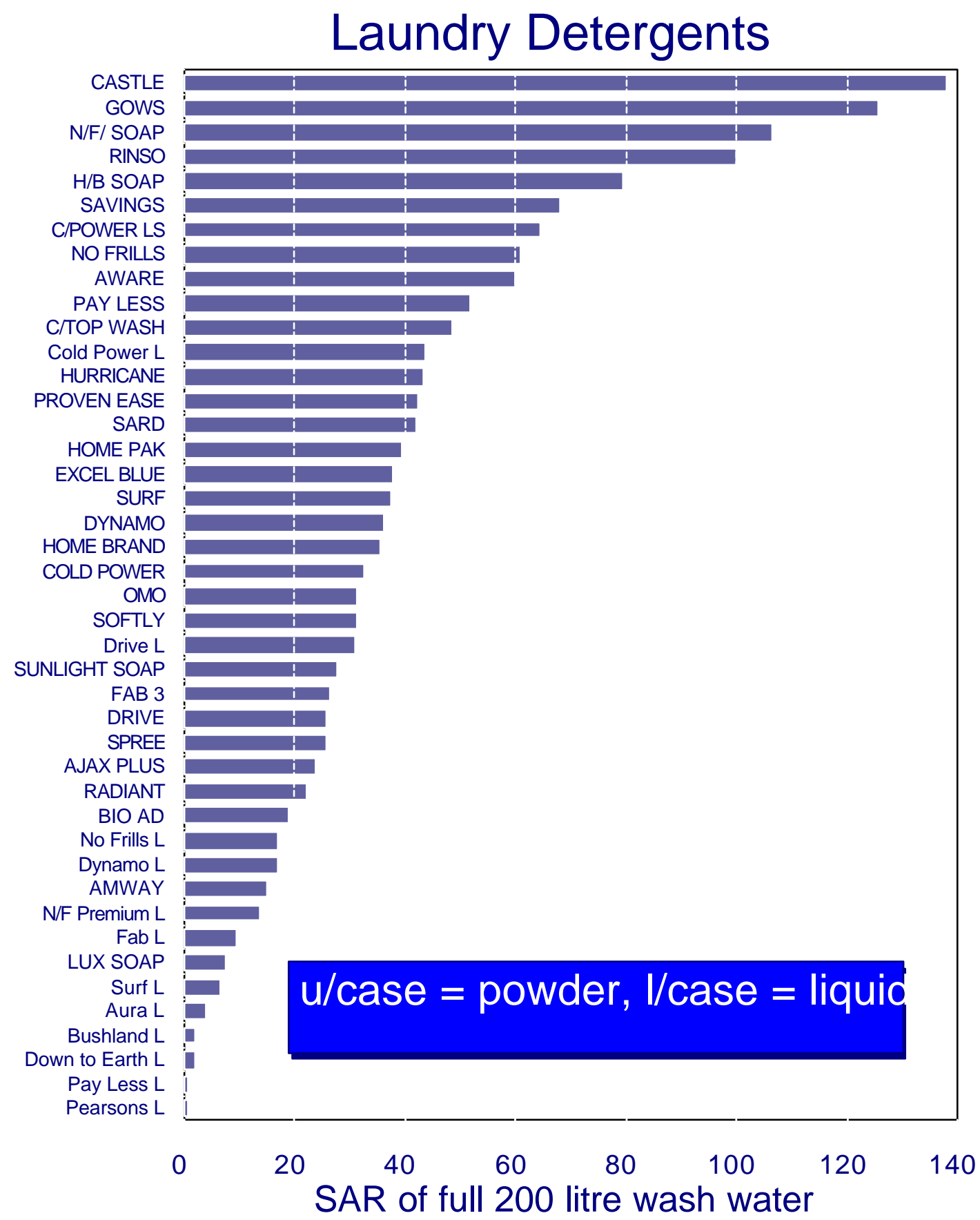

FIG. 3-- Sodium adsorption ratio of laundry detergents tested

\section{Loss of Soil Hydraulic Conductivity}

The results of the various hydraulic conductivity tests indicated that Ksat is reduced when effluent of SAR as low as 3 is disposed of on a number of NSW soils. The problem associated with STE is that SAR 3 effluent is accompanied by low EC. The loss of Ksat with increasing SAR for a chocolate clay loam soil (typic hapludoll) is evident and the results are statistically significant as shown in Fig. 4. 


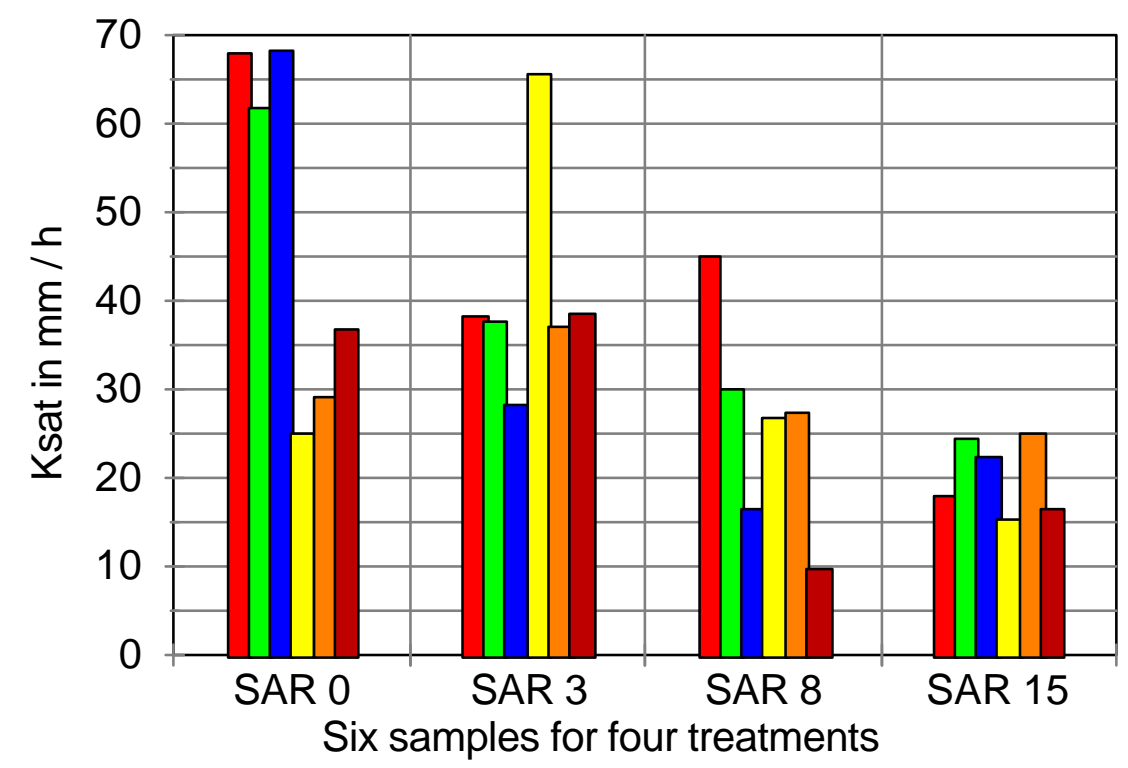

Figure 4. Saturated hydraulic conductivity for surface chocolate soil using disc permeameters. (Bars represent each of the six samples per treatment)

The implications for STE disposal are that the higher the SAR of the effluent, the shorter the life of the drainfield because of the rapid loss of Ksat. Because loss of Ksat is related to soil dispersion, the problem is chemically irreversible and a new disposal field is required. Where surface disposal of STE is performed, loss of Ksat may be reversed by physically disturbing the dispersed layer and incorporating chemical ameliorants. Thus effluent SAR $>3$ requires that assessment of the site includes avoiding dispersion by either reducing SAR in the STE, or ameliorating the site to overcome the dispersion problem.

The critical factor for avoiding loss of Ksat is to prevent the sodium salts from reaching the disposal field or reducing their impact by chemical alteration of the effluent SAR before reaching the soil. In economic terms, reduction of the use of sodium salts in the household is the most effective and efficient prevention. The replacement of sodium based laundry products with those based upon potassium avoids the soil dispersion problems while also avoiding vegetation problems.

The significant variations in town water quality lead to the conclusion that measurements of Ksat cannot be undertaken with water presumed "clean". Uniform chemistry in the water supply industry is neither practical nor economically feasible. Further, from the results of the Ksat testing performed here, the difference between "clean water" (SAR 0) and water of a quality similar to STE indicate that to estimate soil behavioural problems, tests must be undertaken with water of a similar quality to that proposed for disposal.

\section{Cumulative Effects of Domestic Inputs}

The data (Fig. 1 and Table 1) indicate the SAR of the water before it is used within the household. The impact of chemicals used within the household must then be added to the

Domestic Wastewater and the Sodium Factor - R.A. Patterson (1997) 
input water quality. Two indicators have been used to estimate the cumulative effects of households on the sodium content of domestic wastewater. Firstly, the quality of septic tank effluent (Table 2) where rainwater provides the clean water input showed that an average increase of sodium was of the order of $84 \mathrm{mg} \mathrm{L}^{-1}$. Secondly, from the quality of STW effluent (Fig. 2) where the increase in sodium from the clean water to the effluent was of the order of $63 \mathrm{mg} \mathrm{L}^{-1}$. The difference arises from the more conservative use of water in the rainwater supply, however, the mass balance is expected to be similar.

For a typical effluent subsurface drain field of dimensions $0.6 \times 0.6 \times 30 \mathrm{~m}$, the loading of sodium salts onto the soil interface is equivalent to 5.4 tonnes per hectare applied annually. In agronomic terms such a high loading would be considered destructive, but sodium loads are generally ignored by regulators and professionals when planning for on-site disposal.

The change of household laundry detergents away from those which contribute large quantities of sodium to the wastewater stream will reduce the impact of the effluent on its receiving environment. That sodium salts are difficult to remove once placed in the wastewater stream requires that efforts to prevent their entry are the most important measures for reducing environmental impact. A range of laundry products were examined by the author and the results (Fig. 3) indicate that the choice of low sodium products is possible.

\section{CONCLUSIONS}

There is strong evidence that sodium is an environmental hazard and that significant losses of soil Ksat will occur from even short term disposal to susceptible soil profiles. Water with an SAR 3 has been shown to significantly alter the hydraulic conductivity of a clay loam surface soil after a short equilibration period. Extended operation of soil disposal fields with water of higher SAR will lead to deterioration of soil properties and loss of effectiveness in providing final treatment to the effluent. Sodium loading rates reach levels that would be considered unsuitable for soil disposal in other disciplines, yet ignored by regulators and professionals during on-site planning operations.

The solution to the problem lies within the household where the addition of sodium salts can be avoided, rather than futile attempts to alter water chemistry after the event.

Where soil disposal, either subsurface or surface, is proposed, the effects of the effluent must be evaluated with respect to the SAR and EC of the effluent together with the ESP, soil texture and soil structure of the soil profile.

By reducing the quantities of sodium salts used in the household, the life of safe soil disposal fields is lengthened. Reduction in the sodium load can be effectively achieved by choosing laundry products which have a low sodium base (Fig. 3). By such actions, the overall sodium budget is reduced without loss of other amenities to the household and results in benefits with respect to soil disposal of STE.

The data show that for long term protection of the soil's hydraulic conductivity, the need to prevent sodium entering the soil profile is of greater importance than amelioration after the loss has occurred.

Domestic Wastewater and the Sodium Factor - R.A. Patterson (1997) 


\section{REFERENCES}

Jayawardane, N.S. (1979). An equivalent salt solution method for predicting hydraulic conductivities for different salt solutions. Australian Journal of Soil Research. No.17. pp 423-428.

Jayawardane, N.S. and Beattie, J.A. (1979) Effect of salt solution composition on moisture release curves in soils. Australian Journal of Soil Research. No.17. pp 88-99.

National Health and Medical Research Council (1994) Draft Australian Drinking Water Guidelines. Australian Government Publishing Service. Canberra.

Patterson, R.A. (1994) On-site treatment and disposal of septic tank effluent. Ph.D. Thesis. University of New England. Armidale.

Quirk, J.P. and Schofield (1955). The effect of electrolyte concentration on soil permeability. Journal Soil Science, No.6, pp 163-173.

Woodward, C.J. (1987). Lake Illawarrra - a case study for urban runoff pollution controls. Proceedings Seminar on Urban Runoff and Water Quality. Institution of Engineers Australia. Canberra. 